\title{
Textual Deepness and Its Representation
}

\author{
Olga Valuyskaya* \\ Department of English Philology, Volgograd State University, 400062, pr. Universitetskiy 100, Volgograd, Russia
}

\begin{abstract}
The article deals with the textual interpretability and deepness as an objective existing category typical of all textual genres and potentially enabling to classify texts according to their genre belongings and specificity. The proposed operational model of textual deepness is viewed as a universal scheme for textual analysis and characterizes textual deepness as gradual in its nature which discloses the ambiguity or unambiguity of text contents. The texts of different genres are characterized from the standpoint of the language peculiarities and possible formal elements assisting to undergo the procedure on interpretation. In accordance with the proposed operational model of textual deepness, texts are classified into mono-interpretable and multi-interpretable ones with a number of interpretive steps to be introduced while decoding and restoring the textual sense. The number of interpretive steps is predetermined by a genre with its distinctive features. The textual deepness is correlated with a number of genre specific features such as writer's personalization or depersonalization, textual imperativeness and metaphoric richness as well as other prototypical features that organise texts of different genres. The restoration of textual sense is either full or probable. The operational model of deepness is an open system for the further levels to be established.
\end{abstract}

\section{Introduction}

The correlation between text and genre is the focal issue in theoretical linguistics; outlined genre specific features are examined diachronically [1] and viewed as hybrid and mutable in their existence. Genre as a concept is problematic and gives rise to many approaches. A genre based model of language introduced by P. Knapp and M. Watkins [2] is founded on the assumption that text is a social process. The two basic approaches are dominating the sphere of genre theorizing; the first deals with textual factors, the other one concentrates on relations between text and context [3]. Mass media discourse and the changing situation with genres in the era of rapid technological development show that it is theoretically and practically reasonable to study genre not only through textual analysis but through social factors [4]. The correlation between text and genre may be associated with the reader's interpretation; and in this case the reader's competency and generic conventions within a text [5]. W.E. Rogers proposes a literary genre-theory and focuses on genres of lyric, epic and dramatic as interpretive models underlying the interrelation between knowledge, understanding and interpretation [6]. Interpretation of oral literature in anthropological linguistics deals with the description of oral genres of literature; yet the understanding of genre is viewed as a framework for creation and interpretation $[7,8]$. The broad understanding of genre leads to expand the theory investigations to a scale of analyzing not only long written texts and traditional oral folklore texts but speech genres which are steadily expanding [9]. A number of theoretical papers mentioned above give a ground for uniting text, genre and interpretation into an integral whole in terms of textual sense. Text interpretation is the core subject matter that is of interdisciplinary character at the junction of text linguistics, theory of text and textuality $[10,11]$ as well as text analysis and theory of literature. The idea put forward is based on textual categories united into a coherent whole and regarded as textual interpretability referring to its genre and linguistic features. Interpretability represents textual potentiality in a spectrum of plurality and historical alterability of interpretation viewed as a process and a result of comprehension and verbalization. The operational model of textual deepness appears to be the foundation for texts classification into subclasses: monointerpretable and multi-interpretable; the latter in its turn can be subdivided further on into rigid and flexible interpretable texts. In developing textual interpretability, there comes the tripartite operational model of textual deepness with three level gradations accordingly. As a result, the operational character of the model enables one to take into consideration the restoration of textual meaning on the conventional scale of its availability / unavailability [12] which depend on the text type and genre.

\section{Results and Discussion}

\subsection{Mono-interpretable Texts}

* Corresponding author: olgaval@ volsu.ru 
Genre can be defined in terms of conventionality and patterning. The spectrum of prototypical features, which are inherent in text-types of different cultures, exist within a text genre; the features are embodied in linguistic codes, a complex of norms and rules that informs the interpreter about the clues of text comprehension and interpretation. Assumed as system of conventional symbols, a genre correlates with the textual deepness. The first level in the conventional operational model of textual deepness is occupied by texts that may be characterized as monointerpretable. The textual meaning in these texts is unambiguously restorable. The examples of such text are medical prescriptions and cooking recipes, instructions and texts of institutional communication that do not presuppose conflicted information or discrepancy. Any medical prescription presents by itself a written artefact that is individual and practical directive for a single patient; it includes the compounding or dispensing and administration of pharmaceuticals. A medical prescription is an official document with the patient's name and age and amounts of the drugs ordered, it is prescribed individually; though the dosage strength can be either average or personalized if the patient is specific or due to the clinical course. The information to whom the medication is prescribed and the directive how to take a drug are given in the literal sense; and the most essential information is presented. Texts of medical prescriptions (including four parts: superscription, inscription, subscription and signature) undergo neither to verbal contraction or rewording. Meaningful unambiguousness of medical prescriptions derives from the strict demand of preserving people's health which is one of the supreme values. The required doctor's personal seal is considered to be one of the ritual signs symbolizing the text genre. Only one interpretative step is to be taken to restore the sense of a medical prescription: a patient whose name and date of birth are indicated in the text ought to take drugs in accordance with the dosage prescribed by the doctor. By and large, a medical prescription as a text genre is transparent and mono-interpretable.

Another text genre that is closely associated with the previous one is a cooking recipe. These two genres have their main function in regulating activities, order and the way of implementation and accomplishment of something. In this respect a cooking recipe is a description of the way of making with the prescribed indication of necessary ingredients, their amounts (or weights and proportions). As a rule, a text of the cooking recipe is organized according to a formal scheme including the name of a dish (Gazpacho, Fish Broth, Beef Souffle), a list of ingredients, their amounts (1 can condensed cream of mushroom soup, 1 cup finely chopped cooked beef, 2 tablespoons chopped parsley, 6 eggs) and the succession of certain actions that are to be followed in order to cook the dish (combine soup, cheese and seasonings, beat eggs yolks until thick, bake until done). The formal scheme according to which the content of cooking recipes is structured can be patterned in accordance with the following generalized structure: a dish name - a list of ingredients - a set of directions. Thereby, the information is introduced in certain clusters; an interpreter easily decodes the textual meaning via one interpretive step: in order to cook a dish one should necessary amount of ingredients and follow the directions accordingly.

The mono-interpretable level includes texts of all sorts of manuals and handbooks. Thus, for example, a user's manual has clustered information with the prototypical subdivision: instructions, precautionary information, reference information, getting-started information, about the product, technical background. Recipients and clients dwell mostly on those parts of contents which contain the answers to the questions: how to set up / how to operate. Manuals as a text genre usually inform users in full detail about the succession of actions; the succession of actions is rigidly fixed, instructions are obligatory and grammatically presented in the forms of imperatives: "Do not attempt to operate the unit with the door-open". Analysing texts of manuals as a genre gives an opportunity to come to conclusions that rigidity of instructions and their obligatory accomplishment in a strict fixed order present the formal indicators of monointerpretative textual genres and the unambiguity of while restoring the textual meaning of user's manuals.

A textual genre of a patient information leaflet written by a manufacturing pharmaceutical company is highly formal in its structure and has the following typical parts within each pattern: what (invented name) is and what it is used for; before you use; how to use; possible side effects. Verbally these texts are always full of clichés and follow a stereotype and are sampled in accordance with the existing illocution standard that enables a full level of text meaning restoration. The aforementioned parts of a patterned leaflet text are significant since they are connected with the people's lives and health. Unambiguity is a necessary and sufficient feature of this textual genre; the approximate simplified scheme contains specific information about the symptoms of a disease, dosage and therapeutic effects. In general, texts of medical discourse as well as texts of other institutional communication tend to be mono-interpretable as the participants are aimed at mutual understanding. Texts describing standard first aid and personal safety are instructive by character. Let's deal with the description of how to stop a nosebleed taken from a medical website. The verbalized information is organized as in manuals with preferred imperatives: "Sit up straight and tip your head slightly forward; use your thumb and forefinger to firmly pinch the soft part of your nose shut". The aforementioned texts of first aid are of obligatory character and they closely correlate with manuals.

Genre developing has gained its further extension by means of internet available health blogs and a Youtube Channel. Health information accessible to public is more likely to be recommendable rather than obligatory. Although these texts have much in common with those of user manuals, their main messages is to list prescripts or teach patients how to identify and treat common health issues; this genre of online communication has certain conventional features of a dialogue with a potential patient such as the question-answer form (normally including questions like: What does it mean? How much should I apply? Do health benefits overweigh harm?). The dialogue is preceded by a proposal for an appropriate course of actions with some typical phases, for example, 
"5 things you ought to know about ..."; the aim of such advice is to debunk health myths or to introduce acceptable recommendation of how to soothe suffering or else. The genre of an internet medical advice presents by itself clear and unambiguous explanations that are ought to be followed. This genre also belongs to a group of textual genres displacing a mono-interpretive character.

Potentially mono-interpretation is vested in many newspaper and magazine articles which appear under the headings "The Good News" and "The Bad News" and, thus, it orients the information recipients to adjust to a mono-interpretive focus; such headings provide initially a verbalized indicator of the news being positive or negative in nature. The unambiguity of the restored meaning is sometimes emphasized by means of introducing an imperative sentence: Pass the Butter, which in its turn is followed by the sort of information allowing one to finally understand and interpret without any misreading the meaning of the message concerning the negative influence of low-fat diets. The medical commentator summarizes the results of many researches and advises how one should avoid an undesirable effect. Sometimes a newspaper or magazine headline is verbally organized in the form of a binary opposition: "The Good News: The World Economy Is Doing Great. The Bad News: That Means More Greenhouse Gases“. The information presented in the publication is of dual character; on the one hand, emissions are hazardous and harmful, on the other hand, economic growth is significant for national economies. Texts of such types have peculiar genre purposefulness which in its turn defines the strategy of interpretation: we do not expect ambiguous meanings in medical prescriptions, user's manuals or health advice. Such texts usually have conventional features and are regarded as mono-interpretable textual genres; in general, they are of a rigid type and occupy the first level in the proposed operational model of textual deepness.

The final sublevel within the first interpretive operational level is given to the texts of juridical laws and statutes that have acquired their own genre features. The basic genre features of juridical laws and juridical acts are characterised by linguistic exactness, imperativeness, objectivity, disambiguation and official nature; all these exclude possible textual ambiguity within the institutional communication of juridical discourse, and consequently can be regarded as mono-interpretable textual genres with no hidden deep sense; otherwise the texts of laws lose their social validity. The textual peculiarity goes alongside with the information that the juridical act is created and enforced through governmental institutions, regulating behaviour. It seems reasonable to distinguish the following basic textual categories for laws: obligation serving as compulsory for all and controllability presenting the regulation of community relations or a succession of actions of subjects of law. Obligation as a generally binding nature of law can be illustrated by citation the US Constitution:

"No Person shall be a Senator who shall not have attained to the Age of thirty Years, and been nine Years a Citizen of the United States, and who shall not, when elected, be an Inhabitant of that State for which he shall be chosen" (Article I, Section 3). Thus, local residence requirement and age qualification are obligatory for the one to be elected as a member of the Senate. The category of regularity may be justified by quoting Copyright Law: "\$ $201 \cdot$ Ownership of copyright (d) Transfer of Ownership. - (1) The ownership of a copyright may be transferred in whole or in part by any means of conveyance or by operation of law, and may be bequeathed by will or pass as personal property by the applicable laws of intestate succession. (2) Any of the exclusive rights comprised in a copyright, including any subdivision of any of the rights specified by section 106, may be transferred as provided by clause (1) and owned separately. The owner of any particular exclusive right is entitled, to the extent of that right, to all of the protection and remedies accorded to the copyright owner by this title." The cited part demonstrates how transfer of ownership can be regulated according to the law.

The generalised scheme of a law text has the following conventional structural elements: a person of law - a subject matter of law - an action relevant to law - possible sanctions in case of violating a statutory standard. The text of a law acquires in most cases the so called deontic modality that is linguistically represented by such modal operators expressing what is forbidden or allowed, obligatory or required; all these and the strictness of legal language make the texts of laws be mono-interpretable by nature.

Texts of everyday discourse are mostly of the monointerpretable character. It is assumed that texts of everyday communication is contracted and "dashed" by nature; what is meant can be defined as obvious, the spoken form of speech used by interlocutors gives them the opportunity not to thoroughly verbalise what is being discussed; the typical feature of this kind of discourse is the leading role of non-verbal communication, when the information is transmitted via facial gestures, body language, exclamation and so on; in this case verbal communication may be reduced to the minimum, and verbalism serves as an addition to non-verbalism. The specific features of everyday communication besides contraction are intensive situational subjectivity, logic violations as well as breaking the structural continuity of utterances with hesitations and word substitutions: "No ... er ... yes, er... Did it." Moreover, cacology is frequently accompanied with semantic vagueness of lexical units used in speech.

Texts of everyday discourse differ from texts of other types of discourse in the fact that the addressee is to seize the speaker's meaning immediately. The situation of communication by itself serves as a limiting factor, situational rigidity may be manifested as restriction of the membership of communicators and their belonging to a certain community; concrete denotative orientation is typical of an informal conversation.

The analysis of texts that are conventionally displayed within the first level of textual deepness and are most likely to be mono-interpretable permits to outline their general features such as 1) rigidity that is understood as inflexibility and recalcitrance under interpretation, 2) obligation and / or recommendatory nature of prescriptions or actions contributing to the semantic essence of an utterance, 3) regulation nature which 
manifests as the possibility to establish rules guiding an order of some activities.

\subsection{Multi-interpretable Rigid Texts}

In accordance with the idea of a level-based textual deepness, there are texts that belong to a send level of the operational model; the texts are of different textual types and genres if compared to the ones of the first level. We assumed that the texts placed on the second level are multi-interpretable, i.e. more than one possible way of interpretation is possible and acceptable; the question is how completely the hidden textual meaning and implication with no verbal representation can be restored. Consequently, what is meant here is probability or partiality of textual sense restoration. The hidden and inexplicable sense of rigid text is restored nearly to the full or to a hundred-per-cent level. The scope of multiinterpretable rigid texts embraces newspaper and magazine texts, scientific and scholarly papers.

Newspaper and magazine publications are supposedly of the same nature since dailies and weeklies have very much in common taking into consideration the character of texts, genres of periodicals as such; this fact determined the choice of The Time as a source of texts for analysis.

Texts in periodicals have a rather distinct and clear sense structure. The subdivision of this structure falls into the following parts: 1) factual sense substructure when the sense development starts with a certain fact; and the fact is the dominant point of informative presentation, the text explicit the information about a real event, the presented information sets the order of reasoning and inferences; 2) conceptual substructure occurs when the textual sense development starts with the author's conceptual foundation; in this case there occurs fact transformation, but the transformation is of peculiar sort, i.e. it is subdued to the logic of an author's thought. Thus, the sense structure of a periodical text can be developed in its contents either following the fact or the author's conception. The development of the sense textual structure that begin with the fact dominates in newspaper and magazine texts; whereas the textual development beginning with the author's conception occurs if the evolution of the author's idea is marked with special significance, entertainment or paradoxology. The distinctive predomination character of the sense structure in periodical texts is the basis for the hidden sense restoration; though probability sense restoration occurs.

Ambiguity while restoring the textual sense is determined by genre peculiarity of texts belonging to mass-media discourse.

Certain rigidity in interpreting newspaper and magazine texts is closely connected with the fact that the main requirements imposed on mass-media reports are officialism and objectivity coinciding with impartiality. Furthermore, information in newspaper and magazine articles bears a clear-cut social character; it ought to be comprehensible for general addressees. The theory of mass-media information outlines publicity as one of the properties in the process of transmitting information and reaching a large audience, it presupposes availability to all members of the community without any restrictions. Texts referring to mass-media discourse do not possess such properties as paroling, excessive metaphoric nature, all the point that can arouse difficulties in comprehension.

Interpretation ambiguity of mass-media text is possible due to the fact that some periodical genres acquire metaphoricalness and allegorical character which lead to hidden sense and implications. Variorum readings and textual discrepancy are possible since large audiences to whom periodical texts are addressed to do not mean homogeneity of general readers; i.e. any interpreter always introduces and adds some personal sense into the text under interpretation.

Textual deepness in newspapers and magazines can be analysed depending on their genre belongings. All genre diversity of mass-media texts is traditionally subdivided into informative, analytical and artistic-publicistic. Thus, the number of interpretive steps which disclose the textual sense ambiguity is different for each genre groupings. The number of interpretive steps that are to be taken by an interpreter in order to restore the hidden sense of informative textual genres is fewer in comparison with the number of interpretive steps needed for the restoration of the hidden sense within the texts of artistic-publicistic genres; informative texts are of the factual character, whereas the text of pamphlets, essays, sketches are different in terms of conceptualization and metaphorical character. Nevertheless mass-media texts of all genres preserve the main requirement: relative sense transparency; besides there exists the author's disposition to the reader's unambiguous comprehension; it is regarded as the communicative principle of journalism as a documentary system.

The analysis of newspaper and magazine publications demonstrates that not only texts of metaphorical nature can contain hidden and implication senses. If news reports or stories are to be viewed as proper informative genres of journalism, they acquire some typical formal features that are schematically organized in a succession of events which are taking place or have taken place. The main function of these textual genres is to informing the readers. The beginning of the introduced timely events and happenings usually start with the topical information: "Hawaii homes threatened by 1301 earthquakes ..." or "Tokyo - China, Japan and South Korea agreed Wednesday to cooperate on ending South Korea's nuclear program..." and so on. The references to the time and place represent a certain starting point which initiates the information reporting about a past or future happening. The basis of a newspaper or magazine text is formed in the shape of alternating laconic accounts of events. Justifying the idea may be illustrated by examining the article in The Time (May 9, 2018) under the headline "Iranian Lawmakers Burn Paper US Flag in Parliament after Trump Pulls out of Nuclear Deal". The degree of tenseness in the situation is not explicated but introduced in an inexplicable way by underlying that "it was for the first time political observers could remember anything being burnt inside the parliament itself". Another potion of information that has no direct verbal textual presentation is the fact of asking for support from the countries still in deal: "Late Tuesday night, President 
Hassan Rauhani said he'd be sending Iranian Foreign Minister Mohammad Javad Zarif to the countries still in the deal - China, France, Germany, Russia and the United Kingdom". Then, as a reader reconstructs the hidden sense there is only one interpretive step needed in both cases to explicate the implication either of burning the flag inside the parliament or sending the foreign minister to other countries involved into the deal.

A news report as a genre has a set of typical genre peculiarities, among them the omission of the so called writer's self. The news text as a rule develops one topical issue. The main textual function in these genres is imparting information based on facts. These genres do not have such peculiarities as evaluativity, whereas relevance, newsworthiness and social significance distinctive for mass-media discourse in general are implemented. Such mass-media text specificity as editorial classification or rubricating aims readers at relatively unambiguous perception and information interpretation. In mass media discourse any editorial classification turns out to be the prompt for the further more or less rigidity in text comprehension; the classification as such is never verbalized in news stories but serves to assist readers in sense restoration, for example: "Winners and losers" as a rubric has the attitudinal meaning in itself and covers a broad subject by giving a short commentary to the information that is presented. Thus, news reports may introduce pre-text information that restricts their multiinterpretable nature

The post-textual localization of information may also occur in news stories and it can also be a supplement to restrictions in multi-interpretation of mass-media texts. As indicated, the presence of pre-textual and post-textual information in informative mass-media genres is considered to fulfill the function of orienting readers by establishing relative interpretive steps towards relative unambiguity in text comprehension determined by genre specificity.

For the purpose of the operational model of textual deepness proposed in the paper, it should be noted that mass-media texts appear to be impersonal and objective; since objectiveness serves as the foundation for information in the press. The question of reaching absolute objectiveness in communication media is doubtful; there is always some subjective nature, it is interconnected with inserted personal sense which is due to be disclosed be a interpreting reader. It can be defined in relation to the presence of hidden sense that appears in publications produced by writers. It is important to note that thematization in the press when articles are united in accordance with selected particular topics also presupposes the presence of hidden senses. Here is the example of thematization of news stories from one issue; the headlines are as follows "Leaders of China, Japan and North Korea Will Work Together on Denuclearing North Korea", "North Korean Leader Could Be Offered Regime Security", "North Korea Frees 3 Americans". In one particular issue the problem of international relations of North Korea is being thematized. The stories put together suggest that a general reader should come to the conclusion about North Korea being a dangerous state that can really threaten world peace in general and individual foreigners who dare visit it. If viewed in terms of thematization these news stories are not only about the political situation round North Korea but a sign of introducing hidden senses.

Another type of multi-interpretable rigid genre in communication media is the so called "to our readers" information that is the genre of addressing in communication media that has no headlines with diverse discussion topics. Such texts contain not only the reference to a socially significant fact or event; there also exist some comments to the developed news. It should be noted that there is an impersonalized (collective) author but not a personalized writer. There appears to be a generalized writer's image that interfuses with editors' personalities. The presence of the authorized "we" justifies the fact that the text is a result of collaborative writing, the result which depicts the editorial staff as a cohesive whole, and the impersonalized author is involved as an independent intercommunity. The following phrases confirm the aforementioned idea: "late July is also when we launched ..." or "naturally, we were hoping that" and alike, but there also can be the identification: "Ralph Borrello, Manager, Wealth Division".

The leading function of the genre of addressing the readers is to draw attention to a fact or event which can be of some interest according to editors' standpoints. The typical feature of the genre is its publicistic nature that is understood as novelty, newsworthiness and social relevance. The genuine sense of these texts is never coded; on the contrary, it is explicated so as to preserve the social essence of appealing the readers. The distinctive feature of this textual genre is the occurrence of evaluation that is not typical of news stories. In case of estimation presented in the text as a writer's opinion, it acts as a significant element orientating an interpreter to comprehend the given standpoint as unambiguous in its meaning.

Genre and text potentiality of media texts are problematic and variable. There are analytical genres such as stories, essays and reviews; they all, if compared with informational genres, have a diversity of tropes and figures of speech (metaphors, allusions and so on) that contributes to sense increments and ambiguity. It creates a foundation for a more complex interpretation that demands increase in a number of interpretive steps to restore the senses. Thus, for example, allusions in mass media texts can contributively create figurativeness and picturesqueness. The following example may illustrate the idea: "He (Walter Munk) has been described as the greatest ever lived oceanographer and the Einstein of the ocean" - the first interpretive step is associated with the fact that an interpreter is to establish the similarity between the contribution of both scientists; the second interpretive step is linked with the standpoint that the allusion to the outstanding physicist makes the personality of W. Munk comparable in his significance to Albert Einstein as a symbol of genius and an icon figure. The third interpretive step restores the meaning of equality in fundamental and influential works made by both scientists. 
For the analysis of textual deepness in other genres such as essays, pamphlets, lampoons, feuilletons, causeries and commented events more interpretive steps should be implemented to disclose the hidden sense. The focus in these texts is in the writer's opinion; and the writer's personality occupies the front plane; as a rule the individual author's opinion is represented vividly and distinctly.

An essay as a short composition is the most complicated mass media genre which exists in journalism and literature. The essay joins a group of journalism genres within mass communication discourse.

The relative unambiguity of restored hidden sense while interpreting an essay can be provided with the following features of the genre: documentary nature based on facts; criticism representing the personal author's view; reflectivity, i.e. contemplation and thoughtful observation; trustworthiness showing confidentiality. To provide the explanation of indicated features it is reasonable to give some examples. The author's own standpoint is verbally introduced by phrases like: "I authored the piece for ... on a trend I see building in international politics" or "Among those I profiled were ..." The writer usually informs the readers about his attitude to the introduced issues, the whole thread of reasoning outlining the author's standpoint clarifies the textual sense and brings to light the author's concepts, includes argumentative approach and appeals to authoritative sources ("a source I consider highly credible"). The conceptual field, nevertheless, may serve as a ground for ambiguity of restored sense since readers as interpreters may have opposing opinions. Any conception assumes independency, inner-directness and individuality of the edifice. The independency of the standpoint is associated with the freedom of thoughts, determination and proactivity in ideas and conclusions the reader or the interpreter comes to without outside influence. Individuality manifests as a feature of an individual who has specificity if compared to others.

Multi-interpretable rigid texts occupy the conventional second level in the proposed operational model of textual deepness and contain tropes and figures of style; the latter generate particular indicators for an interpreter that "signal" passing the information about the hidden sense. Relative richness in tropes and figures of style that occurs in newspaper and magazine texts is of a limited character and does not impede restoring the textual text. Mass media discourse is traditionally characterized by using dead metaphors that are usually presented in dictionaries and are introduced as standardized language units. Image-metaphors are frequent in essays but this genre is not nucleus for mass communication discourse.

Scientific and scholarly texts can be also referred to multi-interpretable rigid texts. These texts tend to approach the stereotypes of mass media texts. A scientific or scholarly article acquires distinctive informational blocs: a headline with the expression of the main textual idea that directs an interpreter, an abstract depicting the main contents, key words bearing the textual message, an introduction as a preliminary part, the main body disclosing the topic and the solution to an issue, a conclusion with the outcome and result. This clearly structural prototype enables an interpreter to follow a relative straightforwardness of sense presentation in a text. The deepness in academic articles is created by means of terminology richness; an interpreter is to clarify the meaning of a term to initiate the starting point for interpretation. The relative rigidity while interpreting the scientific and scholarly texts is attached to the monosemantic character as the fundamental criterion of a scientific term existing. The formal indicator of textual ambiguity may be based on differences in defining one and the same term within a specific field. Thus, substituting a term with a definition can be another step for an interpreter in order to restore the probabilistic textual sense which is ambiguous a priori. In case of interdisciplinary homonymy, the meaning is restored from the context.

\section{Conclusion}

The proposed operational model enables to classify all textual types and genres according to the category of textual deepness which is the potential contents category typical of all coherent texts. The distinguishing of this category is objectively reasonable in text analysis. The conventional level structure permits to correlate different text types with corresponding levels of deepness and in accordance with the genre peculiarities. The analysed texts of different genres possess a spectrum of features that are schematically represented as formal elements of a complex character.

The operational model may have a number of levels that can be enlarged by introducing numerous genres into interpretative activities of readers as the types of genres are expanding.

The first level is occupied with the mono-interpretable texts with restorable sense from the situation. Monointerpretability is typical of such textual genres as doctors' prescriptions, all sorts of instructions and user manuals, texts of institutional communication, i.e. the situation itself demands the unambiguity of textual sense and excludes the possibility of non-ambiguity. The peculiarity of these texts is their deontic modality (implicit or explicit) that includes the following modality indicators as "compulsory", "permitted" or "forbidden". The syntactical textual level renders the modality by means of imperativeness the proportion of which is high in instructions and manuals. The peculiar feature of such genres lies in fact that they are impossible to be meaningfully compressed or paraphrased. These textual genres do not metaphors; the information is of a factual character, a writer of mono-interpretable texts exists as a social community but not as an individual; the main communication function of mono-interpretable texts is regulative.

The newspaper, magazine and scientific articles are placed on the conventional second level of textual deepness; the main aim of these textual genres is informing, sharing facts and results. These texts also have some deontic modality, sometimes implicit imperativeness that is hidden and does not possess the 
character of exact direction and regulation. The writer's personality starts to individualize and the gradation from the author's depersonalization in news stories to the writer's standpoint in essays is observed. Rigid multiinterpretable texts may undergo the process of sense compression and paraphrasing. The texts of the second level are characterized by gradual enrichment in tropes and figures of speech that contribute to sense augment. The usage metaphoric expressions are limited and it helps not to implicate the textual sense but to create a certain image. The texts of the second level contain factual and conceptual information.

The operational model of textual deepness possesses a gradual character that presupposes that textual deepness develops in the direction of sense ambiguity. The model functions as an open construction enabling to analyse all existing textual genres. The further levels are vacant for multi-interpretable free texts such as proverbs and sayings, aphorisms and texts of literary writings with the exception of modernist and postmodernist poems.

\section{References}

1. I. Nelson, S. Gayk, Exemplaria 27, 1-2 ( 2015)

2. P. Knapp, M. Watkins, Genre, Text, Grammar: Technologies for Teaching and Assessing Writing (2005)

3. E. Hultin, M Westman, Literacy Teaching, Genres and Power. Education Inquiry 4, 2 (2013)

4. N. Rulyova, H. Westley, Digital Journalism 5, 8 (2017)

5. T. Kent, Interpretation and Genre: The Role of Generic Perception in the Study of Narrative Texts. (London and Toronto, 1986)

6. W. E. Rogers, Three Genres and the Interpretation of Lyric. (Princeton, 2014)

7. P. Seitel, The Power of Genre: Interpreting Haya Oral Literature (Oxford, 1999)

8. B. Paltridge, Genre, Frames and Writing in Research Settings (Amsterdam-Philadelphia, 1997)

9. J. M. Swales, Research Genres: Explorations and Applications (Cambridge, 2004)

10. G. McGann, J. J. McGann, The Textual Condition (Princeton, 1991)

11. A. Pettersson, The Idea of a Text and the Nature of Textual Meaning (2017)

12. O. Valuyskaya, Text Interpretation and Textual Interpretive Categories, ASSEHR 97 (2017) 